University of Wollongong

Research Online

Australian Institute for Innovative Materials -

Papers

Australian Institute for Innovative Materials

2012

Physicochemical study of spiropyran-terthiophene derivatives: photochemistry and thermodynamics

Michele Zanoni

Dublin City University

Simon Coleman

Dublin City University

Kevin J. Fraser

Dublin City University

Robert P. Byrne

University of Wollongong, rbyrne@uow.edu.au

Klaudia K. Wagner

University of Wollongong, kwagner@uow.edu.au

See next page for additional authors

Follow this and additional works at: https://ro.uow.edu.au/aiimpapers

Part of the Engineering Commons, and the Physical Sciences and Mathematics Commons

Research Online is the open access institutional repository for the University of Wollongong. For further information contact the UOW Library: research-pubs@uow.edu.au 


\title{
Physicochemical study of spiropyran-terthiophene derivatives: photochemistry and thermodynamics
}

\begin{abstract}
The photochemistry and thermodynamics of two terthiophene (TTh) derivatives bearing benzospiropyran (BSP) moieties, 1-(3,3"-dimethylindoline-6'-nitrobenzospiropyranyl)-2-ethyl 4,4"-didecyloxy-2,2':5',2"terthiophene-30-acetate (BSP-2) and 1-(3,3"-dimethylindoline-6'- nitrobenzospiropyranyl)-2-ethyl 4,4"didecyloxy-2,2':5',2"-terthiophene-30-carboxylate (BSP-3), differing only by a single methylene spacer unit, have been studied. The kinetics of photogeneration of the equivalent merocyanine (MC) isomers (MC-2 and $\mathrm{MC}-3$, respectively), the isomerisation properties of $\mathrm{MC}-2$ and $\mathrm{MC}-3$, and the thermodynamic parameters have been studied in acetonitrile, and compared to the parent, non-TTh-functionalised, benzospiropyran derivative, BSP-1. Despite the close structural similarity of BSP-2 and BSP-3, their physicochemical properties were found to differ significantly; examples include activation energies $\left(E a(M C-2)=75.05 \mathrm{~kJ} \mathrm{~mol}^{-1}, \mathrm{Ea}_{\mathrm{a}}(\mathrm{MC}-3)=100.39 \mathrm{~kJ} \mathrm{~mol}^{-1}\right)$ and entropies of activation $\left(D S z M C-2=43.38 \mathrm{~J} \mathrm{~K}^{-1}\right.$ $\mathrm{mol}^{-1}, \mathrm{DSzMC}_{-3}=37.78 \mathrm{~J} \mathrm{~K}^{-1} \mathrm{~mol}^{-1}$ ) for the thermal relaxation from MC to BSP, with the MC-3 value much closer to the unmodified MC-1 value $\left(46.48 \mathrm{~J} \mathrm{~K}^{-1} \mathrm{~mol}^{-1}\right)$ for this latter quantity. The thermal relaxation kinetics and solvatochromic behaviour of the derivatives in a range of solvents of differing polarity (ethanol, dichloromethane, acetone, toluene and diethyl ether) are also presented. Differences in the estimated values of these thermodynamic and kinetic parameters are discussed with reference to the molecular structure of the derivatives.
\end{abstract}

\section{Keywords}

terthiophene, derivatives, photochemistry, thermodynamics, physicochemical, study, spiropyran

Disciplines

Engineering | Physical Sciences and Mathematics

\section{Publication Details}

Zanoni, M, Coleman, S, Fraser, KJ, Byrne, R, Wagner, KK, Gambhir, S, Officer, DL, Wallace, GG \& Diamond, D (2012), Physicochemical study of spiropyran-terthiophene derivatives: photochemistry and thermodynamics, Physical Chemistry Chemical Physics, 14(25), pp. 9112-9120.

\section{Authors}

Michele Zanoni, Simon Coleman, Kevin J. Fraser, Robert P. Byrne, Klaudia K. Wagner, Sanjeev Gambhir, David L. Officer, Gordon G. Wallace, and D Diamond 
Cite this: Phys. Chem. Chem. Phys., 2012, 14, 9112-9120

\title{
Physicochemical study of spiropyran-terthiophene derivatives: photochemistry and thermodynamics $\dagger$
}

\author{
Michele Zanoni, ${ }^{a}$ Simon Coleman, ${ }^{a}$ Kevin J. Fraser, ${ }^{a}$ Robert Byrne, ${ }^{a}$ \\ Klaudia Wagner, ${ }^{b}$ Sanjeev Gambhir, ${ }^{b}$ David L. Officer, ${ }^{b}$ Gordon G. Wallace ${ }^{b}$ and \\ Dermot Diamond $* a$
}

Received 9th April 2012, Accepted 11th May 2012

DOI: $10.1039 / \mathrm{c} 2 \mathrm{cp} 41137 \mathrm{~g}$

The photochemistry and thermodynamics of two terthiophene (TTh) derivatives bearing benzospiropyran (BSP) moieties, 1-(3,3'-dimethylindoline-6'-nitrobenzospiropyranyl)-2-ethyl

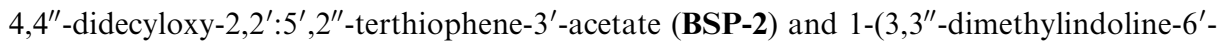
nitrobenzospiropyranyl)-2-ethyl 4,4"-didecyloxy-2,2':5',2"'-terthiophene-3'-carboxylate (BSP-3), differing only by a single methylene spacer unit, have been studied. The kinetics of photogeneration of the equivalent merocyanine (MC) isomers (MC-2 and MC-3, respectively), the isomerisation properties of MC-2 and MC-3, and the thermodynamic parameters have been studied in acetonitrile, and compared to the parent, non-TTh-functionalised, benzospiropyran derivative, BSP-1. Despite the close structural similarity of BSP-2 and BSP-3, their physicochemical properties were found to differ significantly; examples include activation energies $\left(E_{\mathrm{a}(\mathbf{M C}-2)}=75.05 \mathrm{~kJ} \mathrm{~mol}^{-1}, E_{\mathrm{a}(\mathbf{M C}-3)}=100.39 \mathrm{~kJ} \mathrm{~mol}^{-1}\right)$ and entropies of activation $\left(\Delta S_{\mathrm{MC}-2}^{\ddagger}=43.38 \mathrm{~J} \mathrm{~K}^{-1} \mathrm{~mol}^{-1}, \Delta S_{\mathrm{MC}-3}^{\dagger}=37.78 \mathrm{~J} \mathrm{~K}^{-1} \mathrm{~mol}^{-1}\right)$ for the thermal relaxation from MC to BSP, with the MC-3 value much closer to the unmodified MC-1 value (46.48 $\mathrm{J} \mathrm{K}^{-1} \mathrm{~mol}^{-1}$ ) for this latter quantity. The thermal relaxation kinetics and solvatochromic behaviour of the derivatives in a range of solvents of differing polarity (ethanol, dichloromethane, acetone, toluene and diethyl ether) are also presented. Differences in the estimated values of these thermodynamic and kinetic parameters are discussed with reference to the molecular structure of the derivatives.

\section{Introduction}

Nitrobenzospiropyran (BSP) is member of a family of photo/ thermochromic molecules that have been widely studied due to their ability to be switched reversibly under various external stimuli between two molecular states that exhibit dramatically different properties. ${ }^{1-22}$ This behaviour has attracted great interest in terms of possible applications such as optical memory, ${ }^{12}$ biomaterials for targeted therapeutic agents, ${ }^{8}$ components for ophthalmic lenses, ${ }^{9}$ molecular functionalization of micro channels and as optical probes for the analysis of nano-structures in ionic liquids (ILs). ${ }^{14}$

${ }^{a}$ CLARITY: Centre for Sensor Web Technologies, National Centre for Sensor Research, Dublin City University, Dublin 9, Ireland. E-mail:dermot.diamond@dcu.ie; Fax: +35317007995;

Tel: +35317005404

${ }^{b}$ ARC Centre of Excellence for Electromaterials Science and Intelligent Polymer Research Institute, University of Wollongong, Northfields Avenue, Wollongong, NSW 2522, Australia

$\dagger$ Electronic supplementary information (ESI) available: Characterization of BSP-3. Baseline corrected conversion of BSP-1 $\left(10^{-4} \mathrm{M}\right.$ in ACN) to the isomer MC-1. Thermal relaxation profiles of synthesized MC-2 and MC-3 in various solvents. Thermal relaxation profile of MC-1 and MC-3 in ACN at various temperatures. Solvatochromic effect of a range of solvents on BSP-2. See DOI: 10.1039/c2cp41137g
Photochromism is a phenomenon that occurs when electromagnetic radiation is absorbed by a molecule that undergoes a reversible rearrangement between two forms, such as 1-(2-hydroxyethyl)-3,3-dimethylindoline-6' -nitrobenzospiropyran (BSP-1, Fig. 1) $)^{1-13}$ and its equivalent merocyanine form (MC-1), with dramatic accompanying changes in the absorption spectra in the visible region. ${ }^{13}$

Benzospiropyran is a molecule that exists as two heterocyclic functional units connected by a tetrahedral $\mathrm{sp}^{3}$ hybridised carbon atom. This atom co-joins two orthogonal planes comprising an indoline subunit and a benzopyran subunit, the common component for all the spiropyran moieties.

Photo-induced isomerisation processes are well known in the literature. ${ }^{6,7,18-21}$ In spiropyrans, heterocyclic ring cleavage occurs at the $\mathrm{C}_{\text {spiro }}-\mathrm{O}$ bond when exposed to UV light, ${ }^{6,13}$ leading to the formation of the merocyanine (MC) species that can be detected via a striking colour change due to the strong absorbance of the MC isomer in the visible region (Fig. 1). Upon irradiation with white light, the system reverts back to the original BSP form. The MC isomer absorbance is sensitive to its immediate molecular environment, leading to solvent dependant colour changes, and the solvent can also mediate the equilibrium between the isomers. 


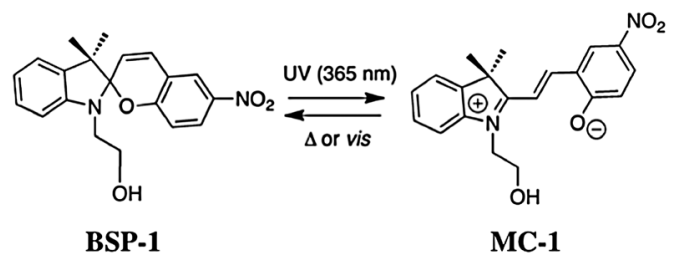

Fig. 1 Molecular structure and isomerisation of 1-(2-hydroxyethyl)3,3-dimethylindoline-6'-nitrobenzospiropyran (BSP-1) spiropyran.

The solvatochromism of various benzospiropyran derivatives has been reported previously including nitro- and methoxysubstituted spiro-moieties. ${ }^{16,17,22}$ Recently, the well-known photo-, thermo- and solvato-chromic properties of benzospiropyran (BSP) and spirooxazine derivatives have been used by our group to provide new insights into the nanostructure of ILs through in situ mediation of their switching behaviour. ${ }^{16,17}$ Furthermore the presence of the phenolate anion in the MC isomer provides a weak binding capacity for certain metal ions (d- and f-elements), and the resulting complexes generate new absorbance bands in the visible region, which are directly influenced by the type of metal ion present. ${ }^{18-21}$

Polythiophenes (PThs) are a class of organic polymeric semiconductors with extremely interesting conductivity, electrochromism and electroluminescence ${ }^{23}$ properties, which have been explored for applications such as electrochemical sensors and energy harvesting devices. ${ }^{24-27}$ From a materials chemistry perspective, they are particularly attractive due to their high chemical stability and relative ease of isolation. ${ }^{25}$ Other interesting PTh properties previously reported in the literature include thermochromism, ionochromism, photochromism and bio-chromism. ${ }^{24-37}$ Chromic variations are generated by conformational changes or folding of the polymer chains, with consequent dramatic variation in the conjugation length of the whole system, which can be monitored using spectroscopy. Substituents connected to the three-aromatic rings backbone can have a considerable effect on the overall conjugation of the system, influencing the properties and the distribution of the $\pi$-electrons in the structure.

As part of our ongoing interest in functionalised PThs, we recently reported the first synthesis of a BSP-functionalised poly(terthiophene) and undertook a detailed study of its complex electrochemical and photochemical properties. ${ }^{38}$ The BSP was attached to the terthiophene monomer (acTTh, Fig. 2) by an acetate linkage (BSP-2, Fig. 2). Given the multiple effects of the spiropyran on the electrochemical behaviour of the poly(terthiophene), we were interested in how these might vary depending on the distance of the spiropyran from the polymer backbone. Therefore, we synthesised the BSP-terthiophene monomer in which the ester linkage was directly attached to the terthiophene moiety (BSP-3, Fig. 2), differing from BSP-2 only by one carbon atom. Prior to studying its electrochemical polymerisation and resulting polymer properties, we deemed it important to determine the photochemical properties of BSP-3 and compare them to BSP-1 and BSP-2.

Therefore, in this work, the photochemical behaviour of the two BSP-functionalised terthiophene monomers, 1 -(3,3' -dimethylindoline- $6^{\prime}$-nitrobenzospiropyranyl)-2-ethyl $4,4^{\prime \prime}$-didecyloxy-2, $2^{\prime}: 5^{\prime}, 2^{\prime \prime}$-terthiophene--3'-acetate (BSP-2) and
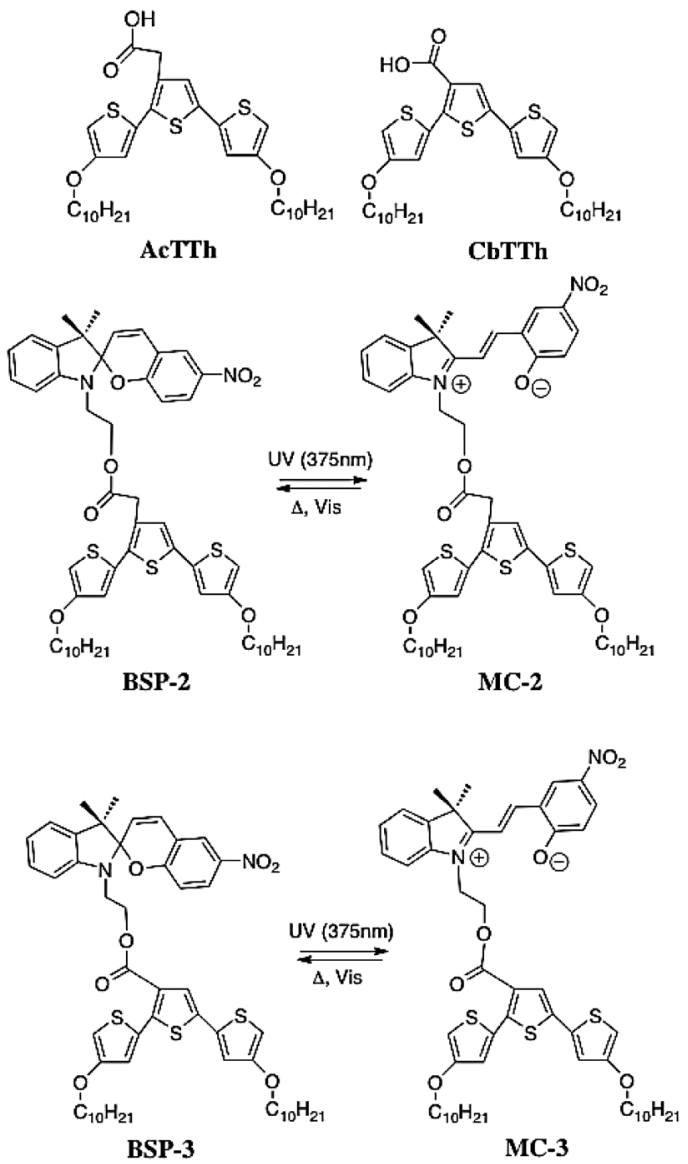

Fig. 2 Structures of the TTh and TTh-BSP derivatives studied: methyl 4,4'-didecyloxy-2, $2^{\prime}: 5^{\prime}, 2^{\prime \prime}$-terthiophene-3'-acetate (AcTTh);

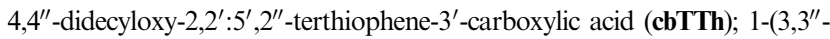
dimethylindoline-6' $6^{\prime}$-nitrobenzospiropyranyl)-2-ethyl 4,4"-didecyloxy$2,2^{\prime}: 5^{\prime}, 2^{\prime \prime}$-terthiophene- $3^{\prime}$-acetate (BSP-2) and 1-(3,3"'-dimethylindoline$6^{\prime}$-nitrobenzospiropyranyl)-2-ethyl $4,4^{\prime \prime}$-didecyloxy-2,2': $5^{\prime}, 2^{\prime \prime}$-terthiophene-3'-carboxylate (BSP-3).

1-(3,3'-dimethylindoline- $6^{\prime}$-nitrobenzospiropyranyl)-2-ethyl

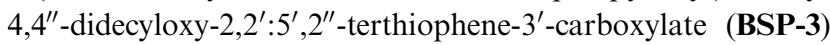
is reported, along with a detailed study of the thermodynamics and kinetics of their photo-isomerization. Their photoswitchable behaviour is reported in comparison to the original parent BSP-1, as this is important for some innovative applications, such as photo-actuated valves incorporated into micro-fluidic manifolds ${ }^{11}$ or light-modulated surfaces for selective cell adhesion/detachment. ${ }^{39}$

\section{Experimental}

\section{Materials}

1-(2-Hydroxyethyl)-3,3-dimethylindolino-6' -nitrobenzopyrylospiran (BSP-1) was purchased from TCI chemicals, Ireland, and was used without further purification. Ethyl $\left(3,3^{\prime \prime}\right.$-dimethylindoline$6^{\prime}$-nitrobenzospiropyranyl)-4,4" -didecyloxy-2,2' $: 5^{\prime}, 2^{\prime \prime}$-terthiophene- $3^{\prime}$-acetate (BSP-2) was synthesised as described previously. ${ }^{38}$

Ethyl (3, $3^{\prime \prime}$-dimethylindoline- $6^{\prime}$-nitrobenzospiropyranyl)$4,4^{\prime \prime}$-didecyloxy-2, $2^{\prime}: 5^{\prime}, 2^{\prime \prime}$-terthiophene- $3^{\prime}$-carboxylate (BSP-3) 
was synthesized as follows: $4,4^{\prime \prime}$-didecyloxy-2, $2^{\prime}: 5^{\prime}, 2^{\prime \prime}$-terthiophene- $3^{\prime}$-carboxylic acid (cbTTh) ${ }^{40}(0.083 \mathrm{~g}, 0.138 \mathrm{mmol})$, dicyclohexylcarbodiimide (DCC) $(0.03 \mathrm{~g}, 0.143 \mathrm{mmol})$ and 4-dimethylaminopyridine (0.0013 g, $0.011 \mathrm{mmol})$ were dissolved in DCM $(12 \mathrm{ml})$ at $0{ }^{\circ} \mathrm{C}$. 1-(2-Hydroxyethyl)-3,3-dimethylindoline-6' -nitrobenzospiropyran BSP-1 (0.04 g, $0.11 \mathrm{mmol})$ in DCM $(10 \mathrm{ml})$ was added dropwise over $30 \mathrm{~min}$ to the stirring solution. After BSP-1 was completely added, the reaction mixture was allowed to reach $20{ }^{\circ} \mathrm{C}$. After a further $90 \mathrm{~min}, 50 \%$ of the DCM was removed under reduced pressure, cold ether $(10 \mathrm{ml})$ was added to precipitate the urea salt of DCC. This precipitate was removed by filtration and the filtrate was reduced to give a brown oil, which was purified on a silica column, eluting with DCM. The resulting product was a yellowish-brown oil, which solidified on standing $(0.081 \mathrm{~g}, 77 \%)$. After purification via column chromatography, the BSP-3 was stored in the dark in a sealed glass vial under nitrogen. Characterisation data are available in the ESI† section.

The solvents used for the photo- and thermo-chromic analyses (acetonitrile (ACN), ethanol (EtOH), toluene (Tol), acetone (Acet), dichloromethane (DCM) and diethyl ether (DetEth)) were Sigma Aldrich HPLC grade, and used without further purification.

\section{Photochemical methods}

To obtain the rate constants of the ring opening process for BSP-1, BSP-2 and BSP-3 to their MC-1, MC-2 and MC-3 forms, the derivatives were continuously monitored during UV irradiation at $375 \mathrm{~nm}$. The samples were kept in the dark for 24 hours to ensure equilibrium in the solvent was reached. Diluted solutions $\left(10^{-4} \mathrm{M}\right)$ of BSP-1, BSP-2 and BSP-3 were exposed to UV light and the spectrum of each was taken at intervals from $t=1$ minute to $t=45$ minutes.

A single exponential model (eqn (1)) was used to determine the ring opening rate constants for BSP-1, BSP-2 and BSP-3.

$$
y=a \times\left(1-\mathrm{e}^{-(k t)}\right)+b
$$

where $y$ is the absorbance at $\lambda_{\max }$ (assumed to be proportional to the concentration of the merocyanime isomer), $a$ is a scaling factor, $k$ is the first order rate constant $\left(\mathrm{s}^{-1}\right), b$ is the baseline offset and $t$ is time (s).

Absorption spectra were recorded using a Perkin Elmer Lambda 900 UV-Vis/NIR spectrometer equipped with a thermostated temperature control system (PTP-1 Peltier System). Photo-conversion of BSP to MC was achieved using an in-house fabricated UV light source consisting of three UV LEDs (Roithner LaserTechnik Gmbh, emission $\lambda_{\max }=375 \mathrm{~nm}$ ). The LEDs were powered from a $3.75 \mathrm{~V}$ current source, which provided an optical power output of $6 \mathrm{~mW} \mathrm{~cm}^{-2}$ from each LED. The white light radiation was provided via a DDL $150 \mathrm{~W}$ source obtained from Polytec GmbH Waldbronn.

To determine the thermodynamic parameters of the samples and obtain an estimation of the transition state equilibrium of activation $\left(K^{\ddagger}\right)$ for the MC $\rightarrow$ BSP equilibrium, standard solutions of BSP-1, BSP-2 and BSP-3 were prepared in concentrations up to $10^{-4} \mathrm{M}$ in acetonitrile. The solutions were stored in volumetric flasks in the dark under nitrogen before the absorbance measurements were acquired. Thermal relaxation analysis of the thermodynamically favoured reversion of MC to BSP was measured at $5{ }^{\circ} \mathrm{C}$ increments from 283 to $308 \mathrm{~K}$ over a period of 1 hour. Samples were irradiated in the dark with the UV-LED system in a sealed quartz cuvette at room temperature for 3 minutes prior to acquisition of the spectra. The study of the BSP $\rightleftharpoons$ MC equilibrium was performed using the LED system in the spectrometer chamber in order to minimise any influence of external light. The MC $\rightarrow$ BSP thermal relaxation typically follows first order kinetics in molecular solvents and the rate is not sensitive to oxygen, but is strongly medium dependent. ${ }^{18-21}$

First-order rate constants for the thermal relaxation were determined in this work using Microsoft Excel Solver, by fitting the absorbance data to eqn (2), where $y$ is the absorbance value at the $\lambda_{\max }, a$ is the absorbance at $t=0, k$ is the rate constant, $t$ is time and $b$ is a baseline offset, as for eqn $(1)^{41}$

$$
y=a \mathrm{e}^{-k t}+b
$$

The Arrhenius equation (3) was used to plot the linear temperature dependence of the rate constant for MC $\rightarrow$ BSP thermal relaxation and find the activation energy $\left(E_{\mathrm{a}}\right)$ and the pre-exponential factor $A$.

$$
\ln k=E_{\mathrm{a}} / R T+\ln A
$$

where $k=$ rate constant $\left(\mathrm{s}^{-1}\right), E_{\mathrm{a}}=$ activation energy $\left(\mathrm{kJ} \mathrm{mol}^{-1}\right), R=$ gas constant $\left(\mathrm{J} \mathrm{mol}^{-1} \mathrm{~K}^{-1}\right), T=$ temperature (K) and $A=$ pre-exponential factor $\left(\mathrm{s}^{-1}\right)$.

Following the generalised BSP $\rightleftharpoons$ MC system (Fig. 1), the Eyring equation (4) was used to determine the thermodynamic properties at the transition state equilibrium of activation $\left(K^{\ddagger}\right)$, entropy of activation $\left(\Delta S^{\ddagger}\right)$, and the enthalpy of activation $\left(\Delta H^{\ddagger}\right)$. A derivative of this equation, eqn (5), can be used to derive the equilibrium of activation $\left(K^{\ddagger}\right){ }^{16,17,22}$

$$
\begin{gathered}
\ln (k / T)=-\Delta H^{\ddagger} / R T+\ln (k / h)+\Delta S^{\ddagger} / R \\
k=\left(k_{\mathrm{B}} T / h\right) K^{\ddagger}
\end{gathered}
$$

where $k=$ rate constant of the forward reaction, $T=$ temperature $(\mathrm{K}), \Delta H^{\ddagger}=$ enthalpy of activation, $\Delta S^{\ddagger}=$ entropy of activation, $R=$ gas constant, $k_{\mathrm{B}}=$ Boltzmann constant and $h=$ Planck's constant.

Thermodynamic activation properties such as $\Delta S^{\ddagger}, \Delta H^{\ddagger}$ and $K^{\ddagger}$ for each MC derivative were calculated using the Eyring equation. Eqn (6) was used to calculate the Gibbs free energy of activation $\left(\Delta G^{\ddagger}\right)$.

$$
\Delta G^{\ddagger}=\Delta H^{\ddagger}-T \Delta S^{\ddagger}
$$

where $\Delta G^{\ddagger}=$ Gibbs free energy of activation $\left(\mathrm{kJ} \mathrm{mol}^{-1}\right), \Delta H^{\ddagger}=$ enthalpy of transition state $\left(\mathrm{kJ} \mathrm{mol}^{-1}\right), T=$ temperature $(\mathrm{K})$ and $\Delta S^{\ddagger}=$ entropy of the transition state $\left(\mathrm{J} \mathrm{K}^{-1} \mathrm{~mol}^{-1}\right)$.

The solvatochromic study was performed at room temperature in 6 different solvent systems (ethanol, toluene, acetone, acetonitrile, diethyl ether and dichloromethane). The solutions (all $10^{-4} \mathrm{M}$ ) were sealed and stored under nitrogen overnight before the analysis was performed. Spectra were taken under controlled temperature conditions using the LED system described above to illuminate the samples. 
Fluorescence (emission) spectra were recorded with a Perkin Elmer Luminescence Spectrometer LS 50B. Solutions diluted up to $10^{-5} \mathrm{M}$ in acetonitrile of the two freestanding TTh molecules, BSP-1, BSP-2 and BSP-3 were made. Excitation wavelengths were set as follows: $358 \mathrm{~nm}$ (acTTh), $362 \mathrm{~nm}$ (cbTTh), $360 \mathrm{~nm}$ (BSP-2 and BSP-3). The solutions were stored in sealed volumetric flasks for 24 hours under nitrogen in the dark. Photo-isomerisation to the relatives MC-1, MC-2 and MC-3 was carried out with in situ LED illumination $\left(\lambda_{\max } 375 \mathrm{~nm}\right)$ for 180 seconds.

\section{Results and discussion}

\section{Material synthesis}

The synthesis of BSP-3 in 77\% yield by a base-catalyzed substitution of BSP-1 onto cbTTh was straightforward and its spectral data (see ESI $\dagger$ ) was consistent with this structure. As expected, its ${ }^{1} \mathrm{H}$ NMR spectrum was near identical to that of BSP-2 except for the absence of the methylene signal at $\delta=7.3$.

\section{Photochromic properties}

It is well known that $\mathbf{M C}$ derivatives typically exhibit negative solvatochromism, meaning that the absorption maximum undergoes a hypsochromic (blue) shift as the solvent polarity increases, due to interactions between the solute and the solvent molecules that increase the energy gap between the $\mathbf{M C}$ ground and the excited states. ${ }^{18-21,42}$ The focus of this study is whether the spectroscopic properties and switching behaviour of the BSP group is affected by attachment of the differing TTh sub-units.

UV-vis spectra of the two spiropyran-functionalised terthiophenes show two major absorbance bands with maxima at $352 \mathrm{~nm}$ and $362 \mathrm{~nm}$ for BSP-2 and BSP-3, respectively (TTh absorbance, BSP contribution not shown ${ }^{38}$ ) and $568 \mathrm{~nm}$ and $572 \mathrm{~nm}$ for MC-2 and MC-3, respectively (MC absorbance), as shown in Fig. 3(a) and (b). All solutions were kept in the dark for 24 hours at $293 \mathrm{~K}$ to establish thermodynamic equilibrium prior to UV illumination. In Fig. 3(a), the absorbance maximum at $c a .360 \mathrm{~nm}$ is greater for MC-2 compared to BSP-2, whereas they are the same for BSP-3 and MC-3 (Fig. 3(b)). This suggests that there is a change in the electronic structure of MC-2 relative to BSP-2, which does not occur with BSP-3/MC-3.

\section{Kinetics of photo-induced ring opening}

Fig. 4(a) and (b) show the spectra used to obtain the $\lambda_{\max }$ values for substitution into the model (eqn (1)), while Fig. 4(c) gives the growth in absorbance over time $(293 \mathrm{~K})$ at the $\lambda_{\max }$ for MC-1, MC-2 and MC-3 (spectra for MC-1 are given in ESI $\dagger$, Fig. S1). The ring opening process analysed using eqn (1) occurs $\sim 1.5$ times faster for BSP-2 compared to BSP-3 $\left(k_{\mathrm{BSP}-2}=4.45 \times 10^{-4} \mathrm{~s}^{-1}\right.$ versus $\left.k_{\mathrm{BSP}-3}=2.85 \times 10^{-4} \mathrm{~s}^{-1}\right)$. For BSP-1 the equivalent rate constant was higher again $\left(k_{\mathrm{BSP}-1}=1.09 \times 10^{-3} \mathrm{~s}^{-1}\right)$, giving an order in terms of speed of ring opening of BSP-1 > BSP-2 > BSP-3.

Extrapolation of the fitted curves using eqn (1) allowed estimation of the steady state absorbance values for the derivatives in ACN. For the formation of MC-2, the model suggests the steady state ( $c a .0 .4$ a.u.) is reached in about 150 minutes while for the formation of MC-3 steady state absorbance is relatively

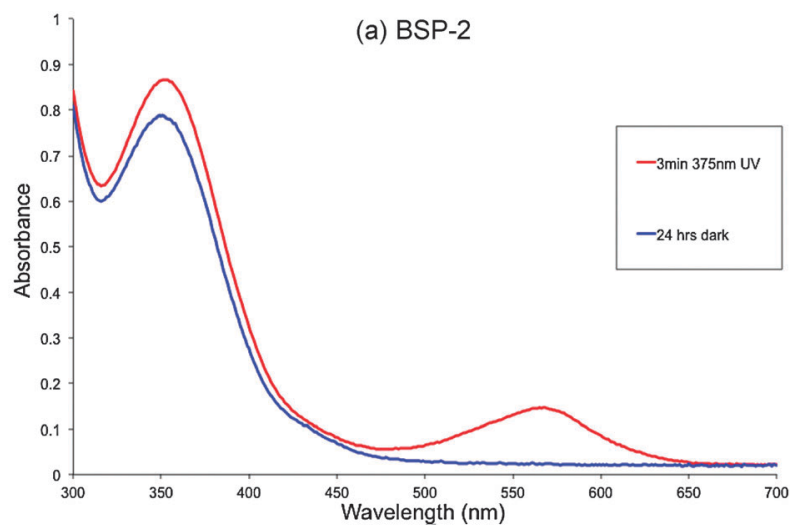

(b) BSP-3

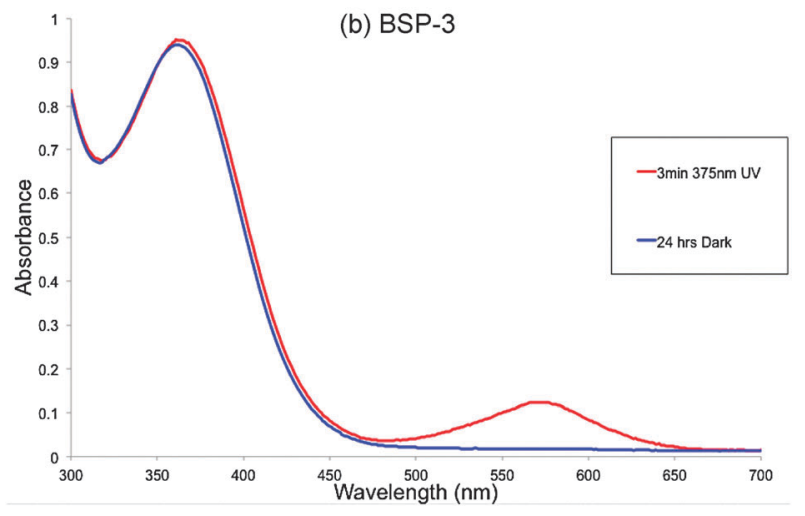

Fig. 3 Baseline corrected UV-vis spectra before and after illumination of $10^{-4} \mathrm{M}$ solutions of (a) BSP-2 with its MC-2 absorption band at $568 \mathrm{~nm}$ and (b) BSP-3 with its MC-3 absorption band at $572 \mathrm{~nm}$, using the $3 \mathrm{UV}$ LED light source with $\lambda_{\max }$ emission $=375 \mathrm{~nm}$; exposure time $=3$ minutes.

constant at $c a .0 .50$ a.u. after about $200 \mathrm{~min}$. This would be expected due to BSP-2 having a faster ring-opening rate than BSP-3 (Fig. 4(c)). Clearly, there is a significant difference in the steady state absorbance of BSP-1 relative to BSP-2 and BSP-3: the detected maximum absorbance for BSP-1 after 45 minutes of exposure to the LED device was 1.84 a.u. at $563 \mathrm{~nm}$ versus 0.31 a.u. at $568 \mathrm{~nm}$ and 0.39 a.u. at $572 \mathrm{~nm}$ for BSP-2 and BSP-3, respectively. This is most likely due to competing absorbance by the TTh moiety present in BSP-2 and BSP-3, which reduces the availability of UV-photons for driving the ring-opening process.

Further indications supporting this statement might be found by comparing the ring opening of BSP-2 and BSP-3. Extrapolation of the curves (Fig. 4(c)) suggests that the process reaches steady state after $c a .150$ minutes for MC-2 and $c a .200$ minutes for MC-3. This model predicts final maximum absorbances for $10^{-4} \mathrm{M}$ acetonitrile solutions of ca. 0.39 a.u. for MC-2, and ca. 0.5 a.u. for MC-3, considerably smaller if compared to derivatives already reported in literature for BSP-1 (1.8 a.u.). ${ }^{42}$ The calculated rate of ring opening in the described process, BSP $\rightarrow$ MC, is fastest for BSP-2 compared to BSP-3, but both are slower than BSP-1 by an order of magnitude.

\section{Kinetics and thermodynamics of ring closure}

Table 1 shows the rate constants for ring closure $(\mathbf{M C} \rightarrow \mathbf{B S P}$ ) over the temperature range 283-308 K for BSP-1, BSP-2 and BSP-3, 

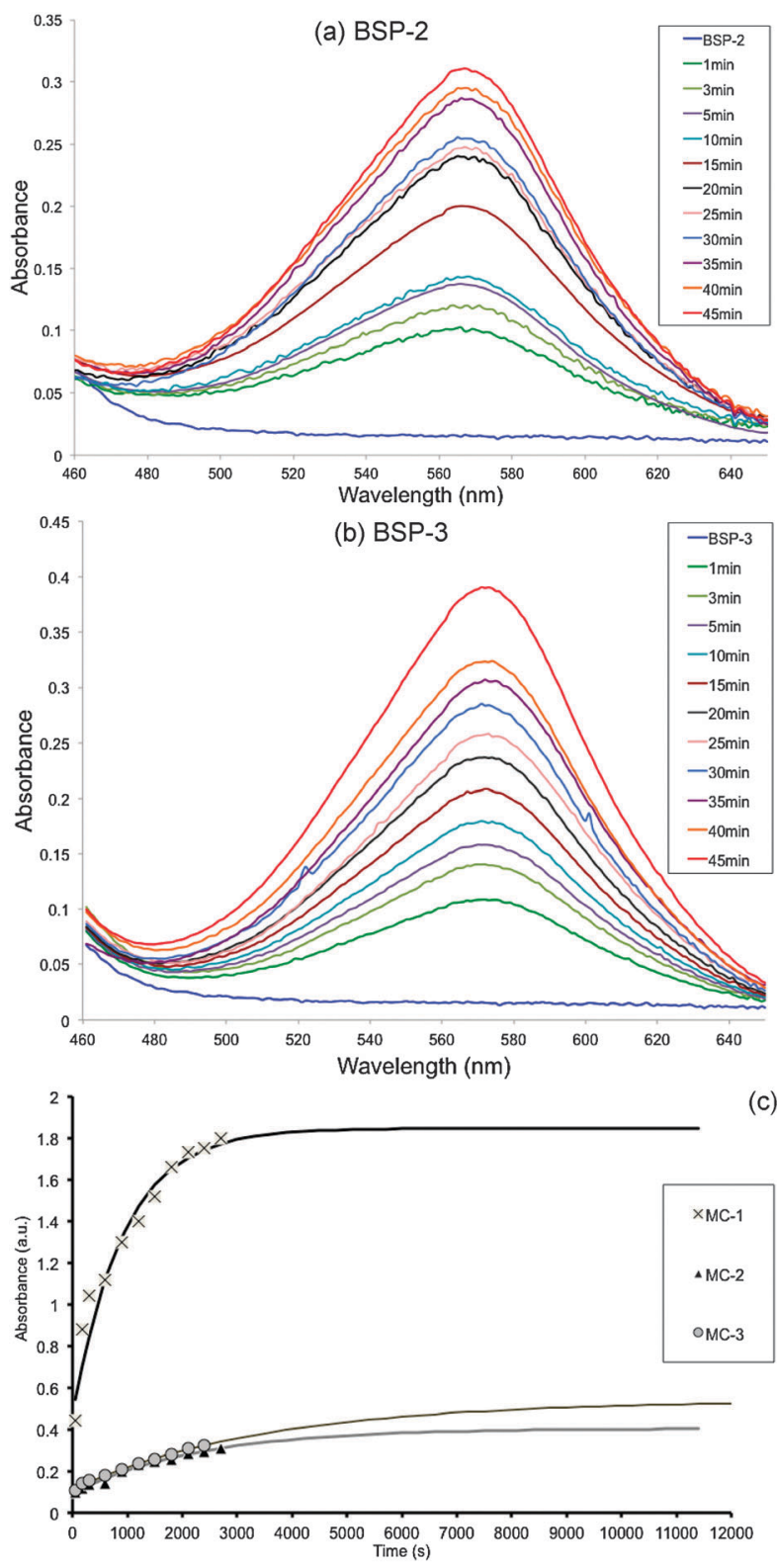

Fig. 4 Exposure effects to $375 \mathrm{~nm}$ UV LEDs: (a) baseline corrected conversion of BSP-2 $\left(10^{-4} \mathrm{M}\right.$ in $\left.\mathrm{ACN}\right)$ to the isomer MC-2. (b) Baseline corrected conversion of spiropyran BSP-3 $\left(10^{-4} \mathrm{M}\right.$ in $\mathrm{ACN}$ ) to the isomer MC-3. (c) Exponential curves extrapolated to steady state for generation of $\mathbf{M C}$ isomers versus time of UV irradiation with experimental results superimposed for MC-2 and MC-3. Values were taken at $\lambda_{\max }$ MC-1 $=563 \mathrm{~nm}, \mathbf{M C - 2}=568 \mathrm{~nm}$, MC-3 $=572 \mathrm{~nm}$

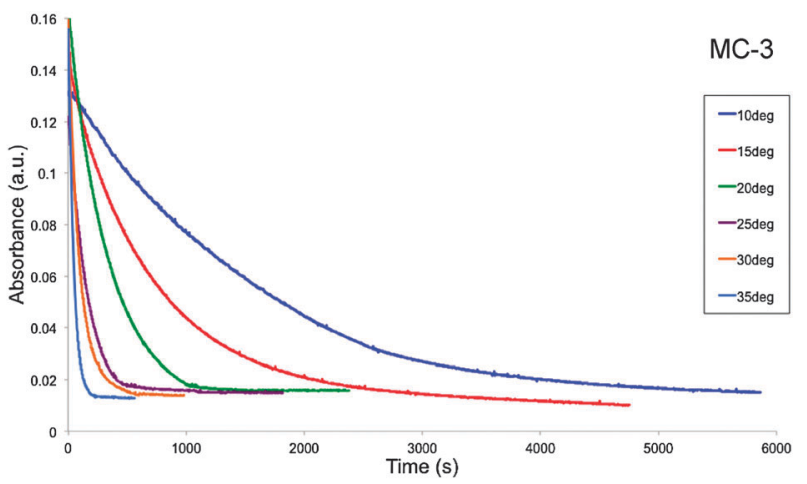

Fig. 5 Thermal relaxation profiles for MC-3 $\left(10^{-4} \mathrm{M}\right.$ in ACN) over the temperature range $283-308 \mathrm{~K}$. Prior to acquisition of the spectra, the solutions were irradiated with the 3 UV-LED device $\left(\lambda_{\max }=375 \mathrm{~nm}\right)$ for $180 \mathrm{~s}$.

and the ratios of the rate constants for each form. The MC-3-MC-2 ratio steadily increases from 0.5 at $283 \mathrm{~K}$ to 1.4 at $308 \mathrm{~K}$, meaning that at $283 \mathrm{~K}, \mathbf{M C}-2$ relaxation is faster, whereas at $308 \mathrm{~K}, \mathbf{M C}-3$ is faster. This pattern of behaviour is repeated for MC-1 compared to MC-2, with the ratio $=0.42$ at $283 \mathrm{~K}$, increasing to 1.15 at $308 \mathrm{~K}$. In contrast, the MC-1/MC-3 ratio remains relatively constant over the temperature range studied, at about 0.8 . These results suggest that the temperature affects ring closure kinetics in a similar manner for BSP-3 compared to the parent BSP-1 (increases around 3-fold), but a different type of dependency is observed with BSP-2 (remains relatively constant). Furthermore, at $283 \mathrm{~K}$ MC-2 reversion to BSP-2 is the fastest for the three derivatives studied, whereas at $308 \mathrm{~K}$, it is the slowest.

Fig. 5 shows the absorbance decrease at $568 \mathrm{~nm}$ for MC- 3 in $\mathrm{ACN}\left(10^{-4} \mathrm{M}\right)$ at different temperatures (similar spectra for MC-2 and MC-1 are given in the ESI $\dagger$, Fig. S3 and S4, respectively), from which the rate constants for ring closing (thermal relaxation) at each temperature were obtained by fitting a first order rate equation.

The resulting Arrhenius and Eyring plots are shown in Fig. 6(a) and (b). From the Arrhenius plots, the activation energy $\left(E_{\mathrm{a}}\right)$ and the pre-exponential factor were derived (Table 2) for the thermal relaxation process. Using Eyring's transition state theory (eqn (4)), the activation thermodynamic parameters, $\Delta S^{\ddagger}$ (entropy of activation), $\Delta H^{\ddagger}$ (enthalpy of activation) and $\Delta G^{\ddagger}$ (Gibbs free energy of activation), for the thermal relaxation process can be estimated (Table 2, Fig. 6(b)).

The Arrhenius and Eyring plots both show that MC-1 and MC-3 exhibit strikingly similar behaviour, with almost identical slopes,

Table 1 Rate constants $k$ and their ratios for MC $\rightarrow$ BSP thermal relaxation for MC-1, MC-2 and MC-3 (10 ${ }^{-4}$ M in ACN) over $283-308$ K averaged from 3 replicates. Standard deviations reported in brackets

\begin{tabular}{|c|c|c|c|c|c|c|c|}
\hline & \multirow[b]{2}{*}{$\lambda_{\max }(\mathrm{nm})$} & \multicolumn{6}{|c|}{$k\left(10^{-3} \mathrm{~s}^{-1}\right)$ in $\mathrm{ACN}$} \\
\hline & & $283 \mathrm{~K}$ & $288 \mathrm{~K}$ & $293 \mathrm{~K}$ & $298 \mathrm{~K}$ & $303 \mathrm{~K}$ & $308 \mathrm{~K}$ \\
\hline MC-1 & 563 & $0.5( \pm 0.002)$ & $1.06( \pm 0.001)$ & $2.2( \pm 0.001)$ & $4.5( \pm 0.0009)$ & $9.04( \pm 0.0009)$ & $18.3( \pm 0.0014)$ \\
\hline MC-2 & 568 & $1.2( \pm 0.002)$ & $2.6( \pm 0.002)$ & $4.3( \pm 0.0009)$ & $8.3( \pm 0.002)$ & $11.7( \pm 0.008)$ & $15.8( \pm 0.007)$ \\
\hline MC-3 & 572 & $0.6( \pm 0.004)$ & $1.5( \pm 0.002)$ & $3.6( \pm 0.001)$ & $5.9( \pm 0.001)$ & $10.9( \pm 0.001)$ & $21.6( \pm 0.002)$ \\
\hline \multicolumn{2}{|c|}{ Ratios MC 1/2 } & 0.42 & 0.40 & 0.50 & 0.52 & 0.77 & 1.15 \\
\hline \multicolumn{2}{|c|}{ Ratios MC 1/3 } & 0.83 & 0.70 & 0.62 & 0.76 & 0.82 & 0.84 \\
\hline \multicolumn{2}{|c|}{ Ratios MC 3/2 } & 0.50 & 0.57 & 0.69 & 0.71 & 0.93 & 1.36 \\
\hline
\end{tabular}



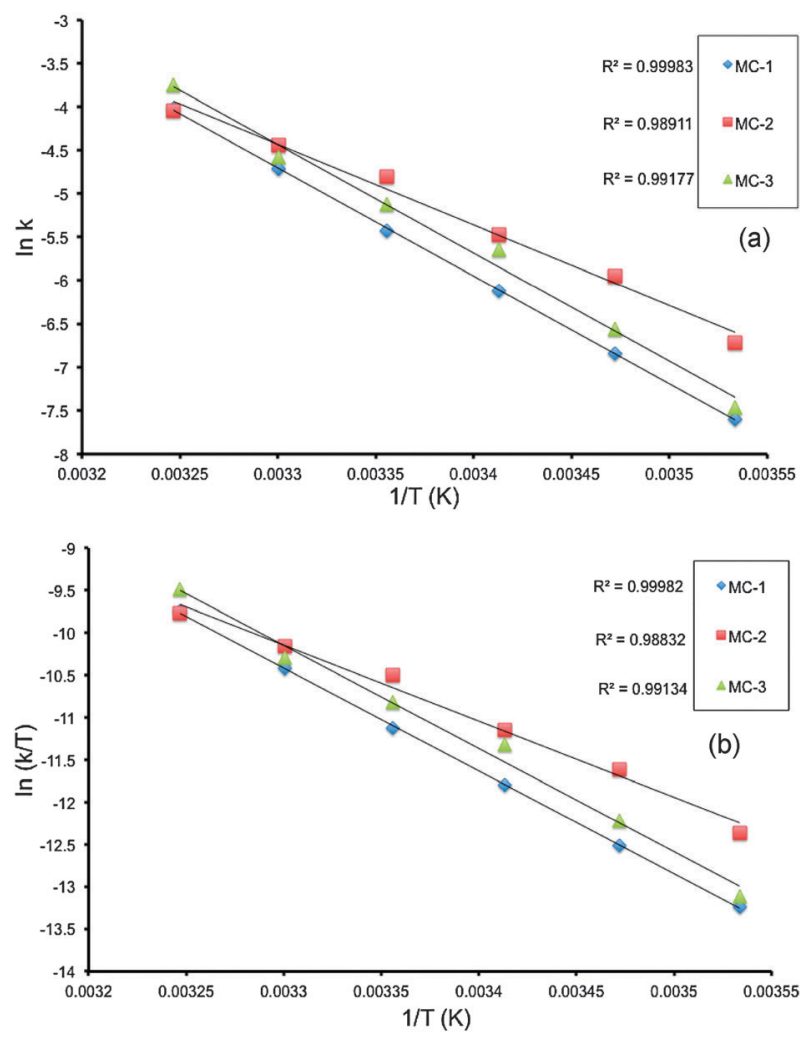

Fig. 6 Comparative (a) Arrhenius plots and (b) Eyring plots for the thermal relaxation process $\mathbf{M C} \rightarrow \mathbf{B S P}$. All solution concentrations were $10^{-4} \mathrm{M}$ in ACN. The values for MC-2, MC-1 and MC-3 were estimated from the thermal relaxation profiles in Fig. S3, S4, ESI $\dagger$ and Fig. 5, respectively.

and a slight offset, whereas MC-2 has a lower slope in both cases, with a higher rate constant at lower temperatures that gradually converges and eventually crosses the other plots. This pattern of behaviour is reflected in the values of the rate constants (Table 1) discussed above, and in the thermodynamic and kinetic parameters extracted from the Arrhenius and Eyring plots (Table 2). Taking each in turn, analysis by Arrhenius theory returns an activation energy for MC-2 that is ca. $25 \%$ lower $\left(75.05 \mathrm{~kJ} \mathrm{~mol}^{-1}\right.$ for BSP-2 compared to $100.39 \mathrm{~kJ} \mathrm{~mol}^{-1}$ for BSP-3, and $101.49 \mathrm{~kJ} \mathrm{~mol}^{-1}$ for BSP-1), and a pre-exponential factor that is smaller by 4 orders of magnitude ( $c a .10^{11}$ vs. $\left.10^{15}\right)$; Eyring theory returns similar Gibb's free energy of activation $\left(85-87 \mathrm{~kJ} \mathrm{~mol}^{-1}\right)$ and equilibrium constants of activation $\left(c a .4-7 \times 10^{-16}\right)$ in all three cases, but the entropy of activation $\left(\Delta S^{\ddagger}\right)$ is negative for $\mathbf{M C}-2\left(-43.38 \mathrm{~kJ} \mathrm{~mol}^{-1}\right)$ and positive for MC-3 (37.78 $\left.\mathrm{kJ} \mathrm{mol}^{-1}\right)$ and MC-1 $\left(46.48 \mathrm{~kJ} \mathrm{~mol}^{-1}\right)$. This quantity (for the process $\mathbf{M C} \rightarrow \mathbf{M C}^{\ddagger}$ ) is related to the degree of order of the system as the MC molecules reorganise within the solvent system due to conformational changes as they pass into the transition state, $\mathbf{M C}^{\ddagger}$. The negative value for $\mathbf{M C 2} \rightarrow \mathbf{M C 2}^{\ddagger}$ suggests that the formation of the transition state results in a more ordered system compared to the equivalent processes for MC-1 and MC-3. Finally, the enthalpy of activation for MC-2 is $73.05 \mathrm{~kJ} \mathrm{~mol}^{-1}$, about 25\% lower than the values for MC-3 and MC-1. These data suggest that the difference in kinetics of ring closing observed for MC-2 may arise primarily for entropic reasons, possibly due to differences in the conformation adopted by MC-2/BSP-2 compared to the other derivatives.

One explanation for these results is the additional methylene group in the BSP-2 linker chain provides a degree of increased flexibility, and the two functional units (BSP and TTh) may be better able to align, for example, through intramolecular $\pi-\pi$ interactions. This would be particularly so when the planar merocyanine isomer is present, and this would favour the adoption of a more ordered configuration, which is consistent with the negative value of $\Delta S^{\ddagger}$ for BSP-2.

This explanation is also supported by the difference in $\Delta H^{\ddagger}$ between the three spiropyrans; $\Delta H^{\ddagger}$ for BSP-2 is $\sim 20 \mathrm{~kJ} \mathrm{~mol}^{-1}$ lower than BSP-1 and BSP-3. This suggests that the MC-2 adopts a ground state conformation somewhat closer to the transition state leading to the spiropyran (BSP-2) than MC-3 does on isomerising to BSP-3. Given that the formation of spiropyran from merocyanine typically requires rotation about the three bonds linking the indoline and phenolate components of the merocyanine, as discussed extensively by Wojtyk et al., ${ }^{43}$ a $\pi-\pi$ interaction between the terthiophene and the phenolate component of MC-2 that brought the phenolate oxygen (in polar solvents) or quinone oxygen (in non-polar solvents) closer to the indoline nitrogen should lower $\Delta H^{\ddagger}$. Such an MC conformation could be determined by $\pi-\pi$ interactions during the ring opening of the spiropyran to form the merocyanine initially.

\section{Solvatochromic effects}

Samples of BSP-2 and BSP-3 were dissolved in selected solvents and kept in the dark for 24 hours before solvatochromic studies were carried out. For this study, a polar protic solvent (ethanol) and polar aprotic solvents (acetone, acetonitrile) were used and their effect compared to non-polar solvents (toluene, dichloromethane and diethyl ether). Fig. 7 shows spectra obtained for MC-3 in a number of solvents after irradiation for 180 seconds with UV light $(375 \mathrm{~nm})$, along with inset photographs of the resulting solutions. In addition, the thermal relaxation rate constants were estimated at $293 \mathrm{~K}$ (Fig. 8(a) and (b), extrapolated from Fig. S2(a) and (b), ESI $\dagger$ )

Table 2 Thermodynamic parameters expressed as a mean of 3 replicates and standard deviation (standard deviations values are reported in brackets) for $\mathbf{M C - 2} \rightleftharpoons \mathbf{B S P - 2}$ and $\mathbf{M C}-3 \rightleftharpoons \mathbf{B S P}-3$ thermal relaxation compared to the results obtained from a reference solution of BSP-1 $10^{-4} \mathrm{M}$ in $\mathrm{ACN}$

\begin{tabular}{lllllllll}
\hline & & \multicolumn{3}{c}{ Arrhenius } & \multicolumn{2}{l}{ Eyring } \\
MC & $\lambda_{\max }(\mathrm{nm})$ & $k_{293}\left(10^{-3} \mathrm{~s}^{-1}\right)$ & $E_{\mathrm{a}}\left(\mathrm{kJ} \mathrm{mol}^{-1}\right)$ & $A\left(\mathrm{~s}^{-1}\right)$ & $\Delta S^{\ddagger}\left(\mathrm{J} \mathrm{K}^{-1} \mathrm{~mol}^{-1}\right)$ & $\Delta G_{293}^{\ddagger}\left(\mathrm{kJ} \mathrm{mol}^{-1}\right)$ & $\Delta H^{\ddagger}\left(\mathrm{kJ} \mathrm{mol}^{-1}\right)$ & $K_{293}^{\ddagger}\left(10^{-16}\right)$ \\
\hline MC-1 & 563 & 2.2 & $101.49( \pm 2.06)$ & $3.51 \times 10^{15}( \pm 2.83)$ & $46.48( \pm 2.92)$ & $86.59( \pm 0.082)$ & $99.04( \pm 2.06)$ & $3.56( \pm 0.108)$ \\
MC-2 & 568 & 4.3 & $75.05( \pm 1.5)$ & $1.35 \times 10^{11}( \pm 0.9)$ & $-43.38( \pm 2.07)$ & $85.17( \pm 0.18)$ & $73.05( \pm 1.5)$ & $6.57( \pm 0.73)$ \\
MC-3 & 572 & 3.6 & $100.39( \pm 3.06)$ & $8.62 \times 10^{15}( \pm 0.24)$ & $37.78( \pm 2.81)$ & $85.94( \pm 0.23)$ & $96.74( \pm 1.42)$ & $5.93( \pm 0.74)$ \\
\hline
\end{tabular}




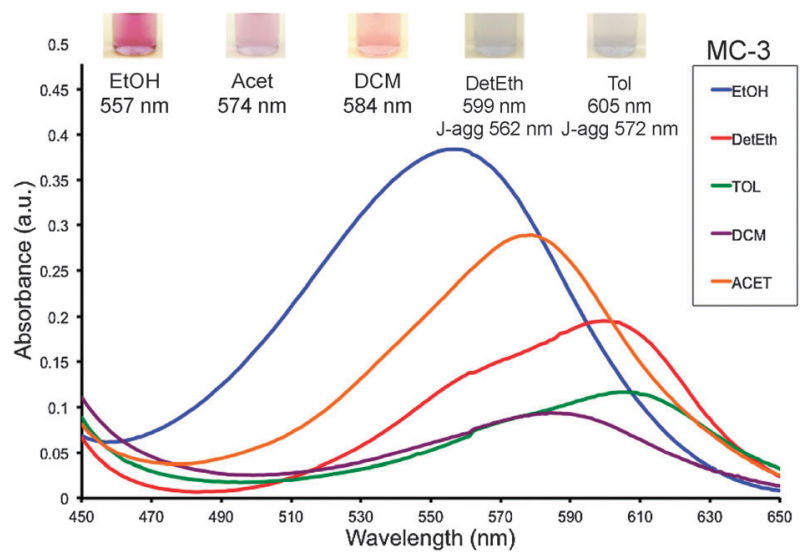

Fig. 7 Solvatochromic effects of $\mathbf{M C - 3}$ in the following solvents: EtOH, Acet, DCM, DetEth and Tol, listed and inset in terms of decreasing polarity. Prior to acquisition of the spectra, the solutions were irradiated with UV-LED device $\left(\lambda_{\max }=375 \mathrm{~nm}\right)$ for $180 \mathrm{~s}$ at $293 \mathrm{~K}$. [BSP-3] $=10^{-4} \mathrm{M}$ in all cases.
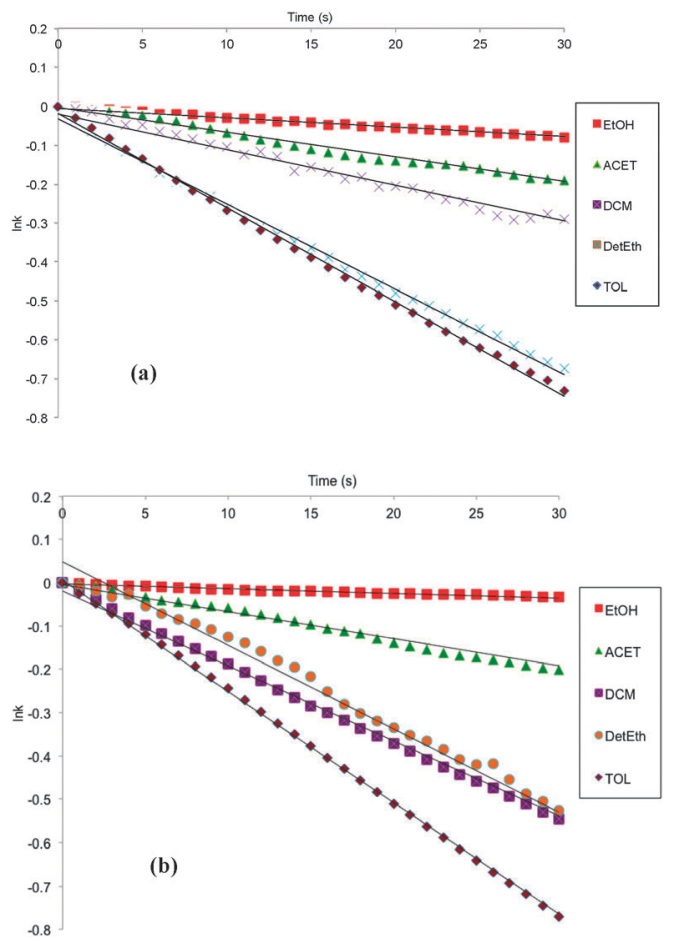

Fig. 8 The $\ln k v s$. time plots used to calculate the rate of thermal relaxation of $10^{-4} \mathrm{M}$ solutions of BSP-2 (a) and BSP-3 (b) in common organic solvents at $293 \mathrm{~K}$.

in each solvent. The formation of J-aggregates (Fig. 7) in nonpolar solvents typical of many BSP derivatives is evident from the appearance of new absorbance bands at $605 \mathrm{~nm}$ and $599 \mathrm{~nm}$ for MC-3, and at $605 \mathrm{~nm}$ and $597 \mathrm{~nm}$ for MC-2 (Fig. S5, ESI $\dagger$ ), in toluene and diethyl ether, respectively.

Table 3 shows clearly that for both MC-2 and MC-3, the $\lambda_{\max }$ is blue-shifted as the solvent polarity increases (negative solvatochromism) from toluene through to ethanol (605 $\mathrm{nm}$ to $552 \mathrm{~nm}$ for MC-2, $552 \mathrm{~nm}$ to $557 \mathrm{~nm}$ for MC-3). As is well established in the literature, merocyanines exhibit negative solvatochromism as a result of both a decrease in the dipole
Table 3 Photo and thermal properties of MC-2 and MC-3 derivatives $\left(10^{-4} \mathrm{M}\right)$ in a selection of solvents. $\lambda_{\max }$ measured after 15 hours in the dark. The thermal 15 relaxation rate constants were calculated by plotting $\ln k v$ s. time, where $k=$ slope

\begin{tabular}{lllllll}
\hline & \multicolumn{5}{l}{ MC-2 } & \multicolumn{1}{l}{ MC-3 } \\
\cline { 2 - 6 } \cline { 5 - 6 } Solvent & $\begin{array}{l}\lambda_{\max } \\
(\mathrm{nm})\end{array}$ & Abs & $k\left(10^{-3} \mathrm{~s}^{-1}\right)$ & $\lambda_{\max }(\mathrm{nm})$ & Abs $k\left(10^{-3} \mathrm{~s}^{-1}\right)$ \\
\hline Ethanol & 552 & 0.42 & 2.4 & 557 & 0.3 & 0.7 \\
Acetonitrile & 568 & 0.12 & 4.3 & 572 & 0.1 & 3.6 \\
Acetone & 570 & 0.44 & 6.3 & 574 & 0.4 & 6.3 \\
Dichloromethane & 587 & 0.13 & 9.2 & 584 & 0.4 & 17.3 \\
Diethyl ether & 597 & 0.29 & 21.9 & 599 & 0.2 & 19.3 \\
Toluene & 605 & 0.42 & 24.3 & 605 & 0.5 & 25.7 \\
\hline
\end{tabular}

moment on electronic excitation and an increase in the dipolar nature of the ground state. ${ }^{43}$ It has also been shown that this tends to be independent of the nature of the N-substituent, and this is indeed the case for MC-2 and MC-3, which show near identical solvatochromic behaviour.

In contrast, the rate constant for ring closure $(k)$ decreases by an order of magnitude from $24.3 \times 10^{-3} \mathrm{~s}^{-1}$ to $2.4 \times 10^{-3} \mathrm{~s}^{-1}$ for MC-2 for increasing solvent polarity, while for MC-3 an even greater rate decrease occurs $\left(25.7 \times 10^{-3} \mathrm{~s}^{-1}\right.$ to $\left.0.7 \times 10^{-3} \mathrm{~s}^{-1}\right)$. The values for the rate constants for ring closure are similar in acetonitrile, acetone, diethyl ether and toluene, implying that solvation of the MC isomers must be quite similar. However, in ethanol this is not the case, as ring closure is four times faster for MC-2.

This implies that, even though the dipolar nature of the MC-2 ground state is similar to that of MC-3 (similar $\lambda_{\max }$ values), the ethanol is acting like a less polar solvent with regard to ring closure rate. If intramolecular $\pi-\pi$ interactions do indeed control the ground state conformation of MC-2, then MC-2 is in effect partly solvated by the $\pi$ bonds of terthiophene, a less polar "solvent", diminishing the full effect of the polar ethanol solvent. Somewhat more surprising is the contrary effect of dichloromethane for which ring closure is almost twice as fast for MC-3 relative to $\mathbf{M C - 2}$, even though they appear to be electronically similar in this solvent. A more detailed study needs to be undertaken to probe the reasons for this behaviour.

\section{Fluorescence spectroscopy}

The presence of intramolecular $\pi-\pi$ interactions in MC-2 would be expected to have a significant impact on the emissive properties of the molecule. The emissions of the terthiophene components of both BSP-2 and BSP-3 and their corresponding merocyanines were investigated since excitation of the molecules at $360 \mathrm{~nm}$ would lead to typical terthiophene emissions $^{26}$ around $450 \mathrm{~nm}$ that overlapped with the edge of the merocyanine absorptions (Fig. 3). The corresponding emission spectra, as well as those of BSP-1/MC-1 and the terthiophene acids are presented in Fig. 9(a) and (b), and the relevant data given in Table 4. A comparison of the emission spectra of the two terthiophenes shows, as expected, that acTTh is blue shifted by $28 \mathrm{~nm}$ (Fig. 9(a), $\lambda_{\text {max,em }}=439 \mathrm{~nm}$ ) compared to cbTTh (Fig. 9(b), $\lambda_{\text {max,em }}=467 \mathrm{~nm}$ ) as a result of the effect of the loss of conjugation of the carboxylic acid. However, both BSP-2 $\left(\lambda_{\text {max }, \mathrm{em}}=464 \mathrm{~nm}\right)$ and MC-2 have 

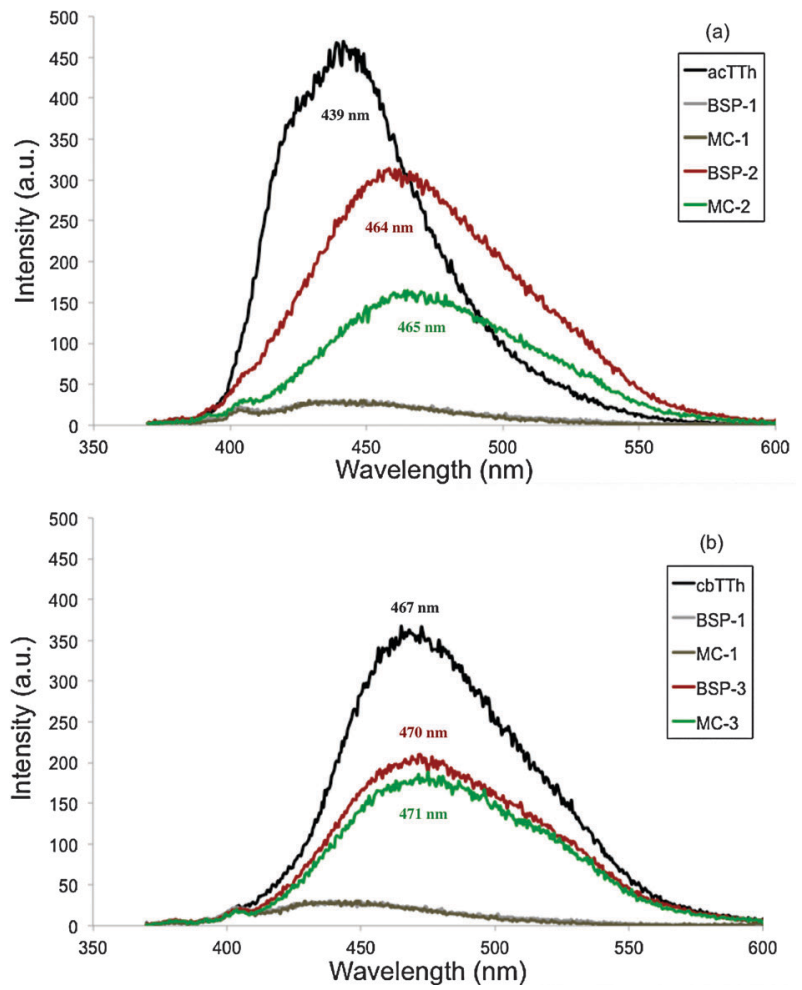

Fig. 9 (a) Emission spectra of acTTh, BSP-1, BSP-2 and their related MC isomers. (b) Emission spectra of cbTTh, BSP-1, BSP-3 and their related MC isomers. All the solutions were $10^{-5} \mathrm{M}$ in ACN and all excitation wavelengths were $360 \mathrm{~nm}$.

Table 4 Parameters derived from the analysis of the emission spectra of acTTh, cbTTh, BSP-2 and BSP-3. Stokes shifts are also indicated

\begin{tabular}{|c|c|c|c|c|}
\hline Molecules & $\begin{array}{l}\lambda_{\max } \mathrm{UV} \text {-vis } \\
\mathrm{cm}^{-1}(\mathrm{~nm})\end{array}$ & $\begin{array}{l}\lambda \text { Excitation } \\
(\mathrm{nm})\end{array}$ & $\begin{array}{l}\lambda_{\max } \text { Emission } \\
\mathrm{cm}^{-1}(\mathrm{~nm})\end{array}$ & $\begin{array}{l}\text { Stokes shift } \\
\left(\mathrm{cm}^{-1}\right)\end{array}$ \\
\hline acTTh & $28090(356)$ & 358 & $22727(440)$ & 5363 \\
\hline cbTTh & $27472(364)$ & 362 & $21413(467)$ & 5874 \\
\hline BSP-2 & $28090(356)$ & 360 & $21598(463)$ & 6492 \\
\hline BSP-3 & $27472(364)$ & 360 & $21276(470)$ & 6196 \\
\hline
\end{tabular}

notably red-shifted ( $\sim 25 \mathrm{~nm}$ ) terthiophene emissions (Fig. 9(a) and Table 4) whilst those of BSP-3 and MC-3 are largely unchanged (Fig. 9(b) and Table 4).

Clearly, there is a much larger structural effect on the emission properties of BSP-2 and MC-2 than can be accounted for by a single carbon atom, and this is fully consistent with the influence of intramolecular $\pi-\pi$ interactions. However, it should be noted that since the emission shift is similar for both BSP-2 and MC-2, similar interactions must be present in both isomers.

Equally significant in this regard is the change in emission intensity for the BSP-2/MC-2 isomers, which is absent for BSP-3/MC-3. While the quantum yields of the molecules were not measured and therefore, it is difficult to draw any conclusions from the relative intensities of the two sets of molecules, the apparent quenching of the MC-2 terthiophene emission is again consistent with a intramolecular $\pi-\pi$ interaction between the planar merocyanine moiety and the terthiophene. This may also explain the increase in the merocyanine absorbance at $355 \mathrm{~nm}$ (Fig. 3(a)) when BSP-2 is exposed to UV light,
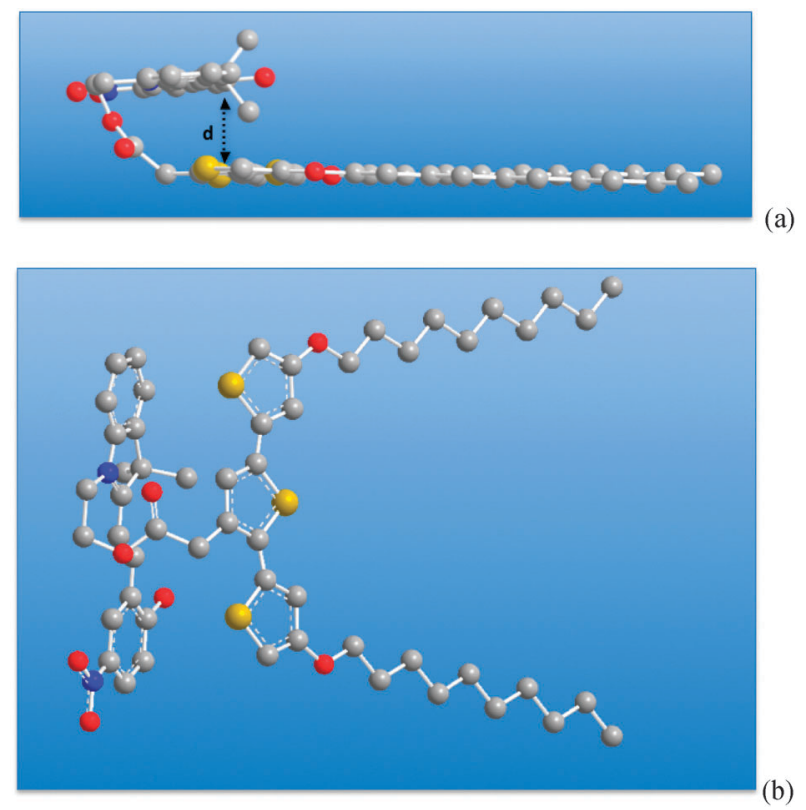

Fig. 10 (a) Side view of MC-2 in a ' $U$ ' arrangement showing the distance ' $d$ ' (3.5-3.7 $\AA$ ) between the aligned MC and TTh moieties and (b) alternative view of the same arrangement of the MC and TTh moieties. Images generated using Chem-3d Ultra V10.0. Atom types carbon (grey), oxygen (red), nitrogen (blue), sulphur (yellow); hydrogen atoms not displayed for clarity.

which does not manifest when the same experiment is performed with BSP-3, suggesting that a new interaction occurs when BSP-2 is switched to MC-2.

Therefore, these results suggest that the extra methylene group present in the BSP-2 linker chain provides a degree of additional flexibility that leads to enhanced intramolecular interaction between the MC and TTh units, most likely through alignment of $\pi$-electrons, as the molecule folds around the linker chain. A 3-d representation of this intramolecular alignment of the MC and TTh $\pi$-electrons is shown in Fig. 10(a) and (b). This was produced by generating the energy minimised MC and TTh sub units in Chem-3D Ultra using standard molecular mechanics and arranging these with the appropriate linker chain, while applying typical constraints for the various bond lengths and angles. This tentatively suggests that is possible for the sub-units to align, with a separation as close as $3.5-3.7 \AA$, which is well within the range for $\pi$-stacking. As indicated by the shift in the emission spectra, such an interaction is also likely between the BSP and TTh moieties in BSP-2, although perhaps not as strongly given the non-planar nature of the BSP unit. In the case of BSP-3/MC-3, the shorter linker group, coupled with the extended conjugation of the TTh- $\pi$ electrons into the carbonyl group prevents this interaction from occurring and the fluorescence and absorbance spectra are not affected in the same manner. A more rigorous ab initio study using molecular orbital theory calculations is currently underway and will be the subject of a separate publication.

This explanation is also consistent with the observed differences in the kinetic and thermodynamic behaviour of the BSP-2 and BSP-3. For example, BSP-3 is similar to BSP-1 in terms of thermal relaxation behaviour. Table 1 shows that the ratio of 
the rate constants remains virtually constant over the temperature range studied (283-308 K), whereas for BSP-2, the ratio increases markedly towards the higher end of the range. This could be explained in terms of disruption of the MC and TTh $\pi$-electron alignment as the system energy increases. Similar explanations have been advanced for observed patterns in the kinetics the thermal relaxation of the merocyanine form of spironaphtooxazine derivatives. ${ }^{44}$

\section{Conclusions}

The photochemical and thermodynamic properties of two derivatives, BSP-2 and BSP-3, incorporating terthiophene units attached to spiropyrans via the indoline nitrogen atom and ester linkers that differ by one methlyene unit have been investigated. In BSP-2, the pyran is separated from the ester group by a methylene group, whereas in BSP-3, the ester group is directly linked to the terthiophene group. This apparently rather small structural difference results in quite striking differences in the characteristics of the derivatives, such as the fluorescence emission spectra (dominated by the terthiophene unit) and the thermal relaxation kinetics of the spiropyran unit. We believe these differences arise from the ability of the $\pi$-electron clouds of the thiophene and spiropyran units to align and form intramolecular $\pi-\pi$ interactions in BSP-2 due to the flexibility of the longer linker chain. In BSP-3, the terthiophene conjugation extends into the ester group of the linker, and this additional rigidity, coupled with the shorter linker length, prevents a similar type of interaction from occurring. We are now developing a new generation of polymers based on these derivatives that could exploit such effects.

\section{Acknowledgements}

MZ, RB and DD acknowledge funding from Science Foundation Ireland (SFI) under the CLARITY CSET award (Grant 07/CE/I1147). KJF acknowledges the European Commission for financial support through a Marie Curie Actions International Re-integration Grant (IRG) (PIRG07-GA-2010268365) and Irish Research Council for Science, Engineering and Technology. We also acknowledge support from the European Commission for funding under grant PIRSESGA-2010-269302. Financial support from the Australian Research Council and access to the Australian National Fabrication Facility are also gratefully acknowledged.

\section{References}

1 Y. Hirshberg, J. Am. Chem. Soc., 1956, 78, 2304-2312.

2 E. Berman, R. E. Fox and F. D. Thomson, J. Am. Chem. Soc., $1959, \mathbf{8 1}, 5605-5608$

3 C. A. Heller, D. A. Fine and R. A. Henry, J. Phys. Chem., 1961, 65, 1908-1909.

4 J. G. Calvert and J. N. J. Pitts, Photochemistry, John Wiley and Sons, Inc., New York, N.Y., 1966.

5 R. Guglielmetti, Stud. Org. Chem. (Amsterdam), 1990, 40, 855-879.

6 V. I. Minkin, Chem. Rev., 2004, 104, 2751-2776.

7 T. Yoshida and A. Morinaka, J. Photochem. Photobiol., A, 1994, 78, 179-183.
8 I. Willner, S. Rubin and Y. Cohen, J. Am. Chem. Soc., 1993, 115, 4937-4938.

9 J. C. Crano, T. Flood, D. Knowles, A. Kumar and B. VanGemert, Pure Appl. Chem., 1996, 68, 1395-1398.

10 S. Stitzel, R. Byrne and D. Diamond, J. Mater. Sci., 2006, 41, $5841-5844$.

11 F. Benito-Lopez, R. Byrne, A. M. Răduță, N. E. Vrana, G. McGuinness and D. Diamond, Lab Chip, 2010, 10, 195.

12 A. S. Dvornikov, J. Malkin and P. M. Rentzepis, J. Phys. Chem., 1994, 98, 6746-6752.

13 H. Bouas-Laurent and H. Dvorr, in Photochromism, ed. D. R. Heinz and B.-L. Henri, Elsevier Science, Amsterdam, 2003, pp. XXVII-LIII.

14 R. Byrne, K. J. Fraser, E. Izgorodina, D. R. MacFarlane, M. Forsyth and D. Diamond, Phys. Chem. Chem. Phys., 2008, 10, 5919-5924.

15 S. Coleman, R. Byrne, S. Minkovska and D. Diamond, J. Phys. Chem. B, 2009, 113, 15589-15596.

16 R. Byrne, S. Coleman, K. J. Fraser, A. Raduta, D. R. MacFarlane and D. Diamond, Phys. Chem. Chem. Phys., 2009, 11, 7286-7291.

17 R. Byrne, S. Coleman, S. Gallagher and D. Diamond, Phys. Chem. Chem. Phys., 2010, 12, 1895-1904.

18 A. K. Chibisov and H. Gorner, Chem. Phys., 1998, 237, 425-442.

19 H. Gorner, Chem. Phys. Lett., 1998, 288, 589.

20 H. Gorner, Phys. Chem. Chem. Phys., 2001, 3, 416-423.

21 H. Gorner and A. K. Chibisov, J. Chem. Soc., Faraday Trans., 1998, 94, 2557-2564.

22 K. J. M. Laidler and J. H. Meiser, Physical Chemistry, Houghton Mifflin, Boston, MA, 3rd edn, 1999.

23 J. Roncali, Chem. Rev., 1992, 92, 711-738.

24 J. Roncali, Chem. Rev., 1997, 97, 173-205.

25 S. Gambhir, K. Wagner and D. L. Officer, Synth. Met., 2005, 154, $117-120$.

26 P. Wagner and D. L. Officer, Synth. Met., 2005, 154, 325-328.

27 M. C. Gallazzi, L. Castellani, R. A. Marin and G. Zerbi, J. Polym. Sci., Part A: Polym. Chem., 1993, 31, 3339-3349.

28 C. H. E. Zhou, Z. Tan, C. Yang and Y. Li, J. Polym. Sci., Part B. Polym. Phys., 2006, 44, 4916-4922.

29 S. H. Hosseini and A. A. Entezami, Polym. Adv. Technol., 2001, 12, 524-534.

30 L. Kumpumbu-Kalemba and M. Leclerc, Chem. Commun., 2000, $1847-1848$.

31 I. Levesque, P. Bazinet and J. Roovers, Macromolecules, 2000, 33, 2952-2957.

32 I. Levesque and M. Leclerc, Chem. Mater., 1996, 8, 2843-2849.

33 I. Levesque and M. Leclerc, Macromolecules, 1997, 30, 4347-4352.

34 F. Raymond, N. Di Cesare, M. Belletete, G. Durocher and M. Leclerc, Adv. Mater., 1998, 10, 599-602.

35 A. Yassar, C. Moustrou, H. K. Youssoufi, A. Samat, R. Guglielmetti and F. Garnier, Macromolecules, 1995, 28, 4548-4553.

36 K. Yoshino, S. Nakajima, M. Onoda and R. Sugimoto, Synth. Met., 1989, 28, 349-357.

37 G. Zotti, R. A. Marin and M. C. Gallazzi, Chem. Mater., 1997, 9, $2945-2950$.

38 K. Wagner, R. Byrne, M. Zanoni, S. Gambhir, L. Dennany, R. Breukers, M. Higgins, P. Wagner, D. Diamond, G. G. Wallace and D. L. Officer, J. Am. Chem. Soc., 2011, 133, $5453-5462$.

39 A. Higuchi, A. Hamamura, Y. Shindo, H. Kitamura, B. O. Yoon, T. Mori, T. Uyama and A. Umezawa, Biomacromolecules, 2004, 5, $1770-1774$.

40 J. M. Locke, S. Gambhir, R. D. Breukers, K. Wagner, K. W. Jolley, G. G. Wallace and D. L. Officer, 2012, manuscript in preparation.

41 D. Diamond and V. C. A. Hanratty, Spreadsheet Applications for Chemistry Using Microsoft Excel, John Wiley and Sons, New York, 1997.

42 J. B. Flannery, J. Am. Chem. Soc., 1968, 90, 5660-5671.

43 J. T. C. Wojtyk, A. Wasey, P. M. Kazmaier, S. Hoz and E. Buncel, J. Phys. Chem. A, 2000, 104, 9046-9055.

44 T. W. Shin, Y. S. Cho, Y. D. Huh, K. D. Lee, W. K. Yang, J. Park and I. J. Lee, J. Photochem. Photobiol., A, 2000, 137, 163-168. 